\title{
AVALIAÇĀO DA INTEGRIDADE ESTRUTURAL DA PONTE SOBRE LAGOA DO ROTEIRO, NO ESTADO DE ALAGOAS
}

\author{
PEREIRA, RODRIGO \\ Engenheiro Civil \\ Strata Engenharia Ltda. \\ Minas Gerais; Brasil \\ rodrigoestruturas@gmail.com \\ DE ALENCAR, CECÍLIA NARDI \\ Estudante \\ Universidade Federal de Minas Gerais \\ Minas Gerais; Brasil \\ cecilia.nardi@hotmail.com
}

\author{
MARTINS, VITOR ARAÚJO \\ Engenheiro \\ Strata Engenharia Ltda. \\ Minas Gerais; Brasil \\ vitoraraujomartins@outlook.com
}

\author{
DO CARMO, ANNE KAROLINE FORTUNATO \\ Engenheira Civil \\ Pontifícia Universidade Católica de Minas Gerais \\ Minas Gerais; Brasil \\ annekarolinefc@gmail.com
}

\section{RESUMO}

A resistência do concreto armado está ligado diretamente com sua interação com o meio, sejam eles químicos, físicos e biológicos, necessitando de cuidados especiais na fase de projeto, construção e operação para que atendam às expectativas de desempenho e durabilidade. Os ambientes marinhos, por sua vez, são nocivos ao concreto por conta da presença de íons de cloro e sulfatos, além da desagregação causada pela água do mar e resíduos que encrustam nas estruturas. Como objetivo principal, este trabalho investigou os agentes causadores da degradação da ponte localizada sobre a Lagoa do Roteiro, no estado de Alagoas. A metodologia do trabalho constituiu em aparelhos de GPS para referência geográfica da ponte, ferramenta Google Earth, registros fotográficos, medições e constatações visuais da Obra de Arte Especial (OAE) para identificar as patologias presentes na estrutura.

Palavras-chave: Concreto, ambientes marinhos, degradação, Obras de Arte Especiais

\section{ABSTRACT}

The strength of reinforced concrete is directly linked to its interaction with the environment, whether chemical, physical and biological, requiring special care in the design, construction and operation phase to meet the expectations of performance and durability. Marine environments, in turn, are harmful to concrete due to the presence of chlorine and sulfate ions, as well as the breakdown caused by seawater and residues that encrust the structures. As main objective, this work investigated the causative agents of the degradation of the bridge located over Lagoa do Roteiro, in the state of Alagoas. The methodology of the work consisted of GPS devices for geographic reference of the bridge, Google Earth tool, photographic records, measurements and visual findings of the Special Art Work (OAE) to identify the pathologies present in the structure.

Keywords: Special Artworks, Structures, pathological manifestation, shelf life.

\section{INTRODUÇÃO}

De acordo com Brasil (2004), o sistema rodoviário nacional é formado por pontes de diversas idades, projetadas e dimensionadas conforme diferentes critérios e solicitadas a suportar um tráfegho de cargas móveis crescente. Deste modo, as pontes devem ser regularmentee inspecionadas levando em conta a capacidade de carga, segurança e conforto dos usuários e, se necessário, realizar melhoramentos e manutenções.

As Obras de Arte Especiais (OAE's) são estruturas que devem ser projetadas e construídas de forma a fornecer, durante sua vida de serviço, condições adequadas de uso e de segurança aos que delas se utilizam. Pode-se afirmar que Pontes de concreto tem sua durabilidade considerando seus insumos constituintes como os agregados, cimento e aço em função de sua fabricação em correlação aos fatores de água/cimento até a aplicação de aditivos, como também sua cura do concreto durante sua fase de construção e na fase de utilização com serviços de conservação e manutenção.

Segundo Lavôr, Linhares e Santos (2016), o concreto é o material mais utilizado na construção civil e esse fato se deve às suas excelentes propriedades mecânicas e a sua disponibilidade. As pontes executadas em concreto armado, durante sua vida útil, necessita de cuidados e de intervenções preventivas e corretivas. De acordo com Araújo (2014) apud 
Lavôr, Linhares e Santos (2016), a deterioração do concreto pode se dar por fatores de origem física, química e biológica.

Sabe-se que a ação do meio ambiente em que uma ponte se encontra é a degradação mais comum que ocorre durante a vida útil da estrutura. Araujo e Panossiam (2010) afirmam que a exposição das estrutura em um ambiente agressivo como o marinho, leva a corrosão pela penetração externa de íons cloreto no concreto de cobrimento, afetando negativamente a estabilidade da estrutura.

De acordo com Santos (2014), a ocorrência de patologias está associada a falhas ocorridas durante a realização de uma ou mais etapas da construção, isto é, podem ser devido ao projeto, execução e/ou utilização da estrutura, podendo manifestar no início, durante ou pós conclusão da obra. Os estudos das patologias das obras civis estão crescendo, uma vez que anos atrás se pensava que as estruturas de concreto iriam durar para sempre. Conforme a norma ABNT NBR 6118/2014, a durabilidade das estruturas depende das características do ambiente em que será construída a estrutura.

As "pontes e viadutos são obras-de-arte especiais que estão sujeitas à ação de diversas patologias da construção, em função do seu uso contínuo e da falta de programas preventivos de manutenção em grande parte dos casos. Essas construções constituem parte essencial de muitos sistemas viários em todo o mundo e, no entanto, apresentam problemas de ordem estrutural que necessitam de solução emergencial.” (Alves et al., 2009).

Este trabalho apresenta como objetivo principal a investigação dos agentes causadores da degradação da ponte localizada sobre a Lagoa do Roteiro, no estado de Alagoas, onde será apresentado um levantamento detalhado das patologias observadas.

\section{ESTUDO DE CASO}

\subsection{Obra Analisada}

O objeto de estudo deste artigo é a ponte sobre o Rio São Miguel (Lagoa do Roteiro), localizada na Rodovia Estadual AL-101, próximo ao município de Barra de São Miguel no Estado de Alagoas.

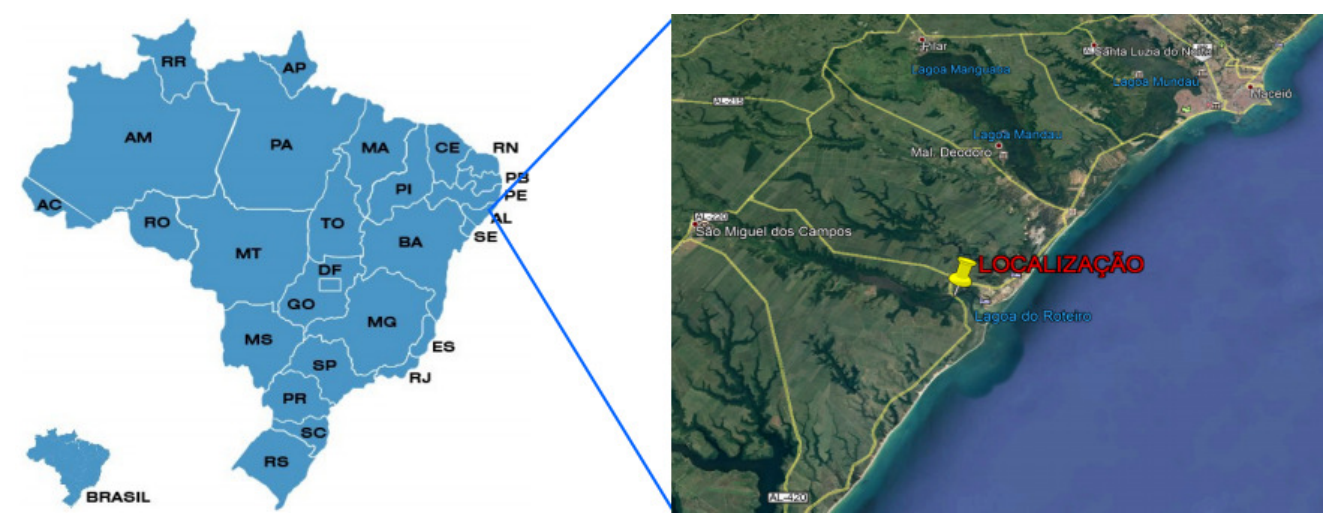

Figura 1: Localização.

De acordo com o Manual IPR 709 de 2004 (Manual de Inspeção de Pontes Rodoviárias), a obra apresenta características semelhantes a das pontes classe 36 tf, que foram executadas entre os anos de 1960 a 1975, com base na largura do Tabuleiro. Porém, os elementos constituintes da ponte, como a viga $\mathrm{T}$ de concreto protendido foram utilizadas após o ano de 1985, apresentando aspecto semelhante das obras com classe 45 tf, no que se refere às obras contruidas no Brasil. Ainda conforme Manual IPR 709 de 2004 (Manual de Inspeção de Pontes Rodoviárias), descreve que as superestruturas em Vigas "I" ou Vigas "T", Pré-moldadas e Protendidas, são as estruturas isostáticas mais econômicas, com grande redução de materias, pode-se vencer vãos de até cerca de $45 \mathrm{~m}$.

\subsection{Inspeção Cadastral}

O sistema longitudinal do tabuleiro é composto por 12 vãos, sendo 10 vãos de 40,00 metros, 1 vão de 39,60 metros e 1 vão de 40,60 metros, possuindo uma extensão de 481,40 metros, e seção transversal com largura de 10,60 metros, conforme representação das figuras 2 e 3 abaixo. 


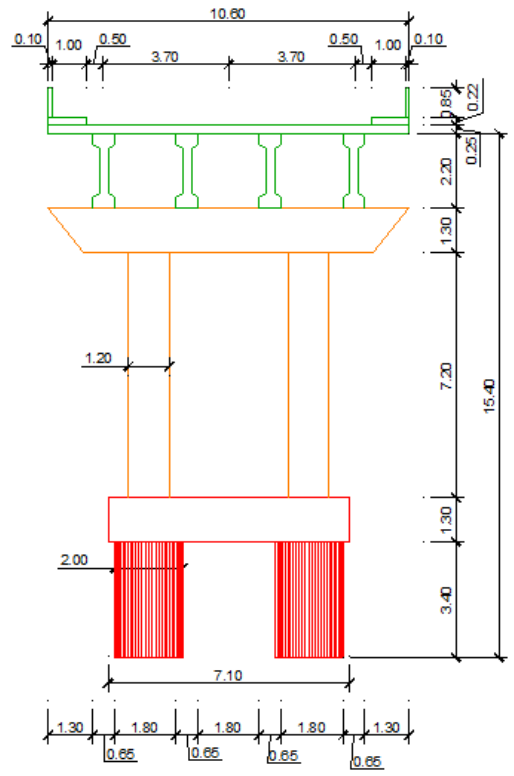

Figura 2: Corte Transversal.

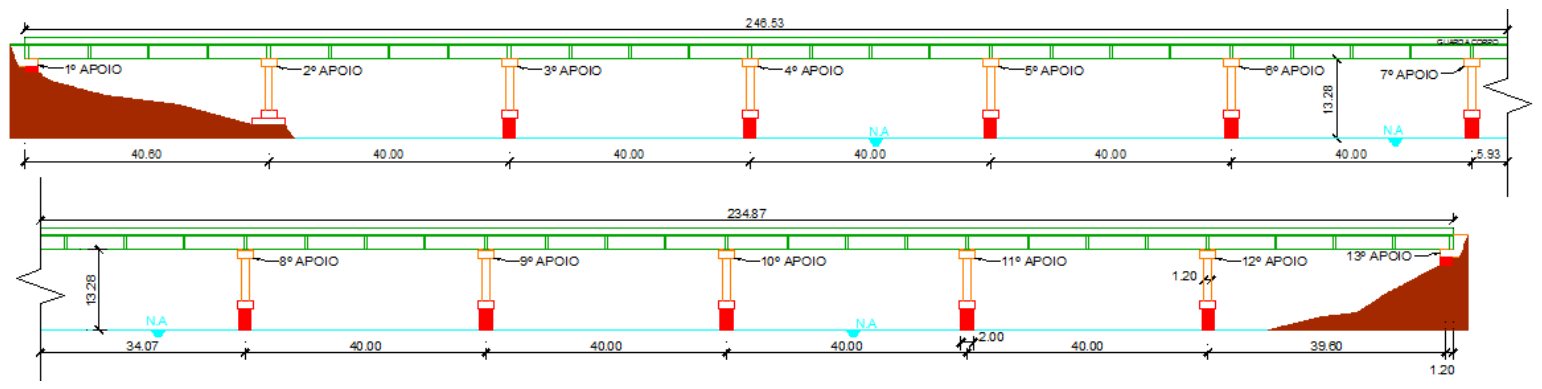

Figura 3: Corte Longitudinal.

\subsection{Metodologia utilizada no estudo}

As Inspeções em Obras de Arte Especiais compreendem a coleta de dados necessários à formulação de um diagnóstico e prognóstico da estrutura, visando manter ou restabelecer os requisitos de segurança estrutural, de funcionalidade, segurança e durabilidade. A Ponte foi inspecionada a luz da norma ABNT NBR NBR 9452 (2016) (Inspeção de pontes, viadutos e passarelas de concreto - Procedimento) e Norma DNIT-10/2004-PRO, identificando as principais deficiencias estruturais, insuficiências estruturais e suas causas possíveis.

Inspeções periódicas e completas são necessárias para manter a operação segura e evitar falhas estruturais e funcionais, conduzida sempre por uma equipe de engenheiros e técnicos com ampla experiência, dando uma resposta rápida estabelecida conforme a criticidade da obra com base nas normas vigentes.

Conforme Campos (2018), a Inspeção Cadastral tem como objetivo a identificação dos elementos, sistemas construtivos, estruturais e funcionas de forma sistematizada e organizada, devendo ser registrados todas informações da obra, buscando informações dos projetos. Além disso, para melhor entendimento na análise da estrutura, os relatórios de conserva e manutenção juntamento com os projetos servirão como base em casos que a estrutura necessitará de intervenção.

A norma ABNT NBR 9452 (2016) denomina-se a Inspeção Rotineira é uma inspeção de acompanhamento periódico, visual, com ou sem a utilização de equipamentos, realizado em prazo não superior a um ano, onde deve ser verificado a evolução das patologias já observadas em inspeções anteriores, bem como novas anomalias, reparos e/ou recuperação efetuadas no periodo.

Foram realizadas Inspeção Cadastral e Inspeção Rotineira, onde identificou-se as patologias presentes na estrutura e dados geométricos levantados, com a utilização de equipamentos como trena manual, trena laser, máquina fotográfica, 
equipamentos de sinalização como cones, barco motorizado, martelo, equipamentos de segurança conforme normas segurança do trabalho, entre outros. Ademais, será apresentado na tabela os dados como suas dimensões e localização.

Tabela 1 - Dimensões e Localização.

\begin{tabular}{c|c|c|c|c}
\hline \multicolumn{3}{c|}{ Dimensões } & \multicolumn{2}{c}{ Localização } \\
\hline Largura $(\mathrm{m})$ & Comprimento $(\mathrm{m})$ & Altura $(\mathrm{m})$ & Coordenadas & Altitude $(\mathrm{m})$ \\
\hline 10,60 & 481,40 & 15,40 & $9^{\circ} 50.229^{\prime} \mathrm{S}$ & 8,00 \\
& & & $35^{\circ} 55.664^{\prime} \mathrm{O}$ & \\
\hline
\end{tabular}

Será exibido a seguir as figuras cadastrais 4 e 5, onde pode-se identificar os elementos componentes na estrutura.

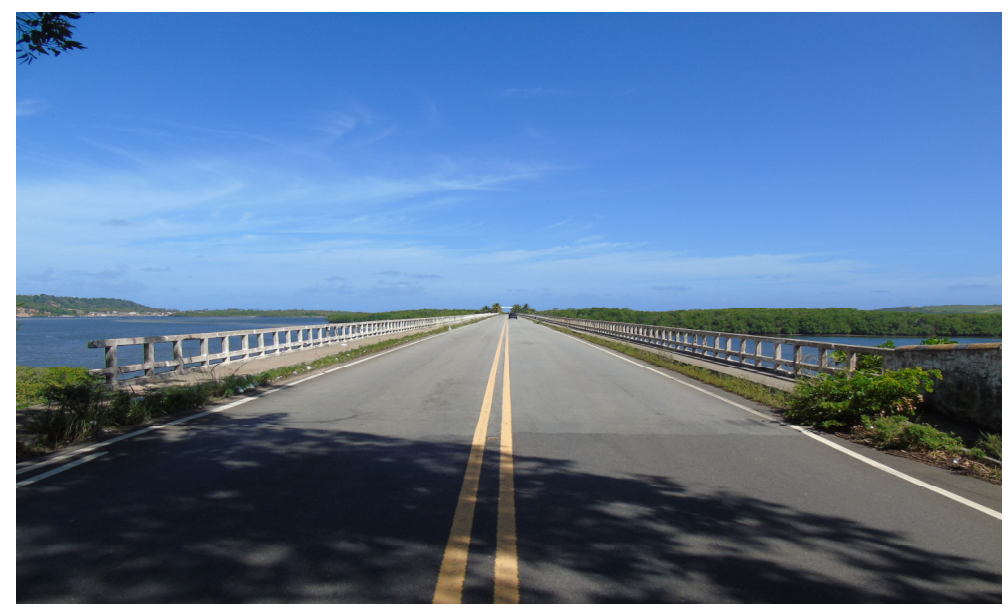

.Figura 5: Vista geral superior da ponte.

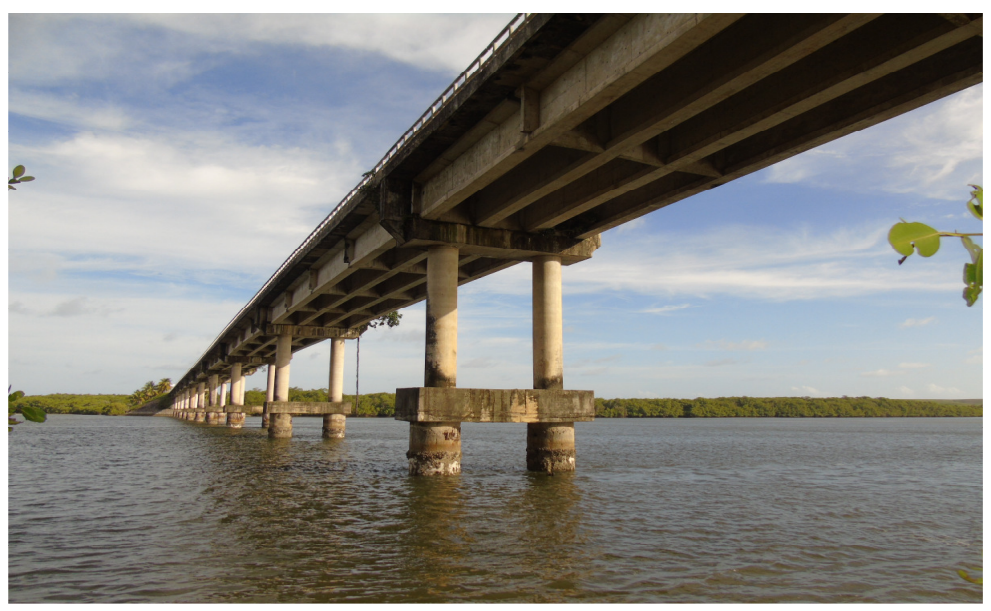

Figura 6: Vista geral inferior da obra.

Os elementos estruturais da Superestrutura são os que recebem direta influência do carregamento móvel atuante, os quais podem se apresentar de várias maneiras ou tipos construtivos. Os sistemas estruturais mais comuns, são formados pelo próprio tabuleiro, por vigas longitudinais, também chamadas de vigamento principal ou longarinas, e vigas transversais, também chamadas de vigamento secundário ou transversinas. A mesoestrutura é formada pelos elementos como aparelho de apoio, travessa de apoio, viga de contraventamento do pilar, pilar e os encontros. Já a infraestrutura é composta por blocos de coroamento, sapatas, estacas, estacões e tubulões (Amorim, Barboza e Barbirato , 2012).

$\mathrm{Na}$ inspeção cadastral realizada, foram identificados os elementos da obra, para melhor gerenciamento dos dados e dimensionamento das patologias levantadas para um resultado de forma proba.

Os elementos identificados na inspeção visual na Superestrutura, Mesoestrutura e Infraestrutura estão descritos na tabela a Seguir. 
Tabela 2 - Elementos constituintes da Obra.

\begin{tabular}{l|l}
\hline & Elementos \\
\hline 1 - Guarda corpo de concreto armado & 8 - Transversina portante de concreto protendido \\
\hline 2 - Guarda rodas antigo DNER & 9 - Viga T de concreto protendido \\
\hline 3 - Pavimento asfáltico & 10 - Aparelho de apoio neoprene fretado \\
\hline 4 - Junta elastomérica de dilatação & 11 - Travessa de apoio de concreto armado \\
\hline 5 - Cortina de concreto armado & 12 - Pilar em colunas de concreto armado \\
\hline 6 - Laje de concreto armado & 13 - Bloco ou sapata de concreto armado \\
\hline 7 - Encontro-Parede frontal portante conc. armado & 14 - Aterro de Acesso \\
\hline
\end{tabular}

\subsection{Inspeção Rotineira}

Através da Inspeção Rotineira é possível detectar e evitar a evolução das patologias presentes na estrutura, criando uma série de possibilidades de porporcionar maneiras de garantir maior vida útil e desempenho da estrutura, diminuindo os custos a longo prazo para uma futura reabilitação.

As pontes exigem manutenção periódica para permanecerem seguras e em serviços, as inspeções ajudam a identificar os elementos que precisam de reparo ou substituição. Quando é encontrada uma condição que pode afetar a capacidade da estrutura de transportar as cargas previstas, uma classificação de carga é concluída e o tráfego que atravessa a estrutura pode ser limitado até que a condição possa ser corrigida ou substituída.

Além disso, Medeiros, Andrade e Helene (2011), expõe que a ausência de manutenção preventiva elevará o custo numa progressão geométrica de razão igual a cinco, conhecido como regra de 5 ou lei de sitter, demonstrado na figura 7 , ou seja o quanto antes detectar a anomalia mais fácil e menos oneroso será o tratamento de recuperação.

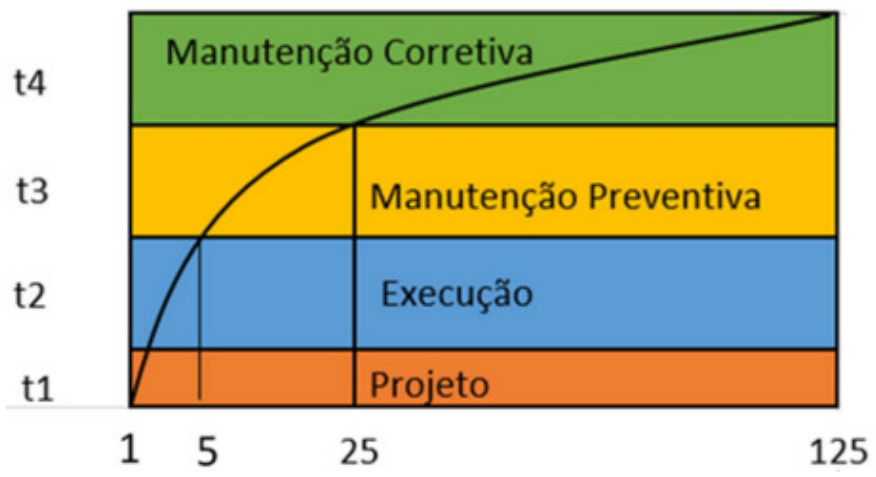

Figura 7 - Evolução dos custos em função da utilização da estrutura em que a intervenção é realizada, Helene (2003).

As deficiências funcionais na maioria das circunstâncias são as responsáveis pelas insuficiências estruturais, essas deficiências estão correlacionadas ao projeto, fase de construção ou até mesmo na fase de utilização com a ausência de trabalhos de conserva e manutenção, apresentado na (Tabela 3) abaixo.

Tabela 3 - Relação das Deficiências Funcionais.

\begin{tabular}{l}
\hline \multicolumn{1}{c}{ Deficiências Funcionais } \\
\hline 1 - Ponte sem acostamento \\
\hline 2 - Calçada para pedestres inexistente \\
\hline - Pingadeira inexistente \\
\hline 4 - Guarda-rodas obsoleto \\
\hline - Pilar em canal de navegação sem proteção \\
\hline
\end{tabular}

Toma-se conhecimento que as Obras de Arte Especiais (OAE's) existentes no Brasil, não são conservadas como os pavimentos asfálticos, que no qual sempre foram as prioridades. As deficiências funcionais identificadas são uma mostra para conhecimento de projetistas que as obras antes de serem projetadas devem ser estudadas de forma que sua durabilidade torna-se maior. Em busca de novos desafios e de conhecimento técnico sobre as inspeções, engenheiros e profissionais da área de estruturas, juntamente com pesquisadores de universidades, devem desenvolver novas maneiras 
de se tornar as inspeções mais seguras e precisas. Nos dias atuais várias tecnologias estão sendo utilizadas no Brasil, como os drone, onde se consegue obter informações como registos fotográficos e dados geométricos georreferenciados.

No Manual IPR 709 de 2004 (Manual de Inspeção de Pontes Rodoviárias), na página 237, apresenta o quadro com a Classificação da condição da OAE segundo os parâmetros estrutural, funcional e de durabilidade, a classificação segue o estabelecido na Tabela 4, que correlaciona essas notas com a condição da obra e caracteriza os problemas detectados.

Tabela 4 - Classificação da condição da OAE segundo os parâmetros estrutural, funcional e durabilidade.

\begin{tabular}{|c|c|c|c|c|}
\hline Nota & Condição & Caracterização Estrutural & $\begin{array}{c}\text { Caracterização } \\
\text { funcional }\end{array}$ & Caracterização de durabilidade \\
\hline 5 & Excelente & $\begin{array}{l}\text { A estrutura apresenta-se em } \\
\text { satisfatórias, com defeitos } \\
\text { irrelevantes e isolados. }\end{array}$ & $\begin{array}{c}\text { A OAE apresenta } \\
\text { segurança e conforto aos } \\
\text { usuários. }\end{array}$ & $\begin{array}{l}\text { A OAE apresenta-se em perfeitas } \\
\text { condições devendo ser prevista } \\
\text { manutenção de rotina. }\end{array}$ \\
\hline 4 & Boa & $\begin{array}{l}\text { A estrutura apresenta danos } \\
\text { pequenos e em áreas, sem } \\
\text { comprometer a segurança } \\
\text { estrutural. }\end{array}$ & $\begin{array}{c}\text { A OAE apresenta } \\
\text { pequenos danos que não } \\
\text { chegam a causar } \\
\text { desconforto ou } \\
\text { insegurança ao usuário. }\end{array}$ & $\begin{array}{l}\text { A OAE apresenta pequenas e } \\
\text { poucas anomalias, que } \\
\text { comprometem sua vida útil, em } \\
\text { região de baixa agressividade } \\
\text { ambiental. }\end{array}$ \\
\hline 3 & Regular & $\begin{array}{l}\text { Há danos que podem gerar } \\
\text { deficiência estrutural. Não há } \\
\text { sinais de comprometimento da } \\
\text { estabilidade da obra. Recomenda- } \\
\text { se acompanhar os problemas. } \\
\text { Intervenções podem ser } \\
\text { necessárias em médio prazo. }\end{array}$ & $\begin{array}{l}\text { A OAE apresenta } \\
\text { desconforto ao usuário, } \\
\text { com defeitos que } \\
\text { requerem ações de } \\
\text { médio prazo. }\end{array}$ & $\begin{array}{l}\text { OAE apresenta pequenas e poucas } \\
\text { anomalias que comprometem a sua } \\
\text { vida útil, em região de moderada à } \\
\text { alta agressividade ambiental; a } \\
\text { OAE apresenta moderadas a } \\
\text { muitas anomalias, que } \\
\text { comprometem sua vida útil, em } \\
\text { região de baixa agressividade } \\
\text { ambiental. }\end{array}$ \\
\hline 2 & Ruim & $\begin{array}{l}\text { Há danos que comprometem a } \\
\text { segurança estrutural da OAE, } \\
\text { sem risco iminente. Sua evolução } \\
\text { pode levar ao colapso estrutural. } \\
\text { Necessita de intervenções } \\
\text { significativas em curto prazo. }\end{array}$ & $\begin{array}{c}\text { OAE com } \\
\text { funcionalidade } \\
\text { visivelmente } \\
\text { comprometida, com } \\
\text { riscos de segurança ao } \\
\text { usuário, requerendo } \\
\text { intervenções de curto } \\
\text { prazo. }\end{array}$ & $\begin{array}{c}\text { A OAE apresenta moderadas a } \\
\text { muitas manifestações patológicas, } \\
\text { que comprometem sua vida útil, } \\
\text { em região de alta agressividade } \\
\text { ambiental. }\end{array}$ \\
\hline 1 & Crítica & $\begin{array}{l}\text { Há danos que geram grave } \\
\text { insuficiência estrutural e } \\
\text { elementos estruturais em estado } \\
\text { crítico e risco tangível de colapso } \\
\text { estrutural. Necessita de } \\
\text { intervenção imediata. }\end{array}$ & $\begin{array}{c}\text { A OAE não apresenta } \\
\text { condições funcionais de } \\
\text { utilização. }\end{array}$ & $\begin{array}{l}\text { A OAE encontra-se em elevado } \\
\text { grau de deterioração, apontando } \\
\text { problema já de risco estrutural e/ou } \\
\text { funcional. }\end{array}$ \\
\hline
\end{tabular}

Paralelamente, a norma ABNT NBR 9452 (2016), apresenta um maior detalhamento na classificação da condição da OAE, considerando a relevância da anomalia e o elemento estrutural onde a mesma foi detectada. Bem como apresenta as consequências de dano em cada tipo de elemento conforme pontos a seguir:

- Elemento principal (P): cujo dano pode ocasionar o colapso parcial ou total da obra;

- Elemento secundário (S): cujo dano pode ocasionar ruptura localizada;

- Elemento complementar (C); cujo dano não causa nenhum comprometimento estrutural, apenas funcional na OAE.

A tabela 5 tem como objetivo balizar a identificação dos tipos de elementos nas estruturas de acordo com a norma em questão. 


\section{CBPAT 2020 \\ CONGRESSO BRASILEIRO DE PATOLOGIA DAS CONSTRUÇÕES \\ DE 15 A 17 DE ABRIL | FORTALEZA - CE}

Tabela 5 - Caracterização dos elementos estruturais segundo relevância no sistema estrutural (ABNT NBR 9452:2016).

\begin{tabular}{|c|c|c|c|c|c|c|c|}
\hline \multirow{2}{*}{\multicolumn{3}{|c|}{ Elemento }} & \multicolumn{5}{|c|}{ Sistema Estrutural } \\
\hline & & & \multirow{2}{*}{$\begin{array}{c}\begin{array}{c}\text { Duas } \\
\text { vigas }\end{array} \\
\mathrm{P}\end{array}$} & \multirow{2}{*}{$\begin{array}{c}\text { Grelha } \\
\mathrm{P} \\
\end{array}$} & \multirow{2}{*}{$\begin{array}{c}\text { Caixão } \\
- \\
\end{array}$} & \multirow{2}{*}{\begin{tabular}{|c|} 
Laje \\
- \\
\end{tabular}} & \multirow{2}{*}{$\begin{array}{c}\text { Galeria } \\
-\end{array}$} \\
\hline \multirow{3}{*}{ Superestrutura } & \multirow{2}{*}{ Viga } & Longarina & & & & & \\
\hline & & Transversina & S & S & S & S & $\mathrm{S}$ \\
\hline & & Laje & $\mathrm{S}$ & $\mathrm{S}$ & $\mathrm{P}$ & $\mathrm{P}$ & $\mathrm{P}$ \\
\hline \multirow{3}{*}{ Mesoestrutura } & & Travessas & $\mathrm{P}$ & $\mathrm{P}$ & $\mathrm{P}$ & $\mathrm{P}$ & - \\
\hline & & Pilares & $\mathrm{P}$ & $\mathrm{P}$ & $\mathrm{P}$ & $\mathrm{P}$ & - \\
\hline & Apar & relho de apoio & $\mathrm{P}$ & $\mathrm{P}$ & $\mathrm{P}$ & $\mathrm{P}$ & - \\
\hline \multirow{3}{*}{ Encontros } & & Cortina & S & S & $\mathrm{S}$ & $\mathrm{S}$ & - \\
\hline & Laje & e de transição & $\mathrm{S}$ & $\mathrm{S}$ & $\mathrm{S}$ & $\mathrm{S}$ & $\mathrm{S}$ \\
\hline & & Iuros de ala & $\mathrm{S}$ & $S$ & $\mathrm{~S}$ & $\mathrm{~S}$ & $\mathrm{~S}$ \\
\hline \multirow{3}{*}{ Infraestrutura } & & Blocos & $\mathrm{P}$ & $\mathrm{P}$ & $\mathrm{P}$ & $\mathrm{P}$ & $\mathrm{P}$ \\
\hline & & Sapatas & $\mathrm{P}$ & $\mathrm{P}$ & $\mathrm{P}$ & $\mathrm{P}$ & $\mathrm{P}$ \\
\hline & Estac & cas e tubulões & $\mathrm{P}$ & $\mathrm{P}$ & $\mathrm{P}$ & $\mathrm{P}$ & $\mathrm{P}$ \\
\hline \multirow{2}{*}{ Complementares } & & Irreira rígida & $\mathrm{C}$ & $\mathrm{C}$ & $\mathrm{C}$ & $\mathrm{C}$ & $\mathrm{C}$ \\
\hline & & uarda-corpo & $\mathrm{C}$ & $\mathrm{C}$ & $\mathrm{C}$ & $\mathrm{C}$ & $\mathrm{C}$ \\
\hline
\end{tabular}

Por seguinte, serão apresentados os registros fotográficos com as principais anomalias presentes na obra e adição de notas de acordo com a norma ABNT NBR 9452:2016 em relação aos parâmetros estruturais, parâmetros funcionais e parâmetros de durabilidade.

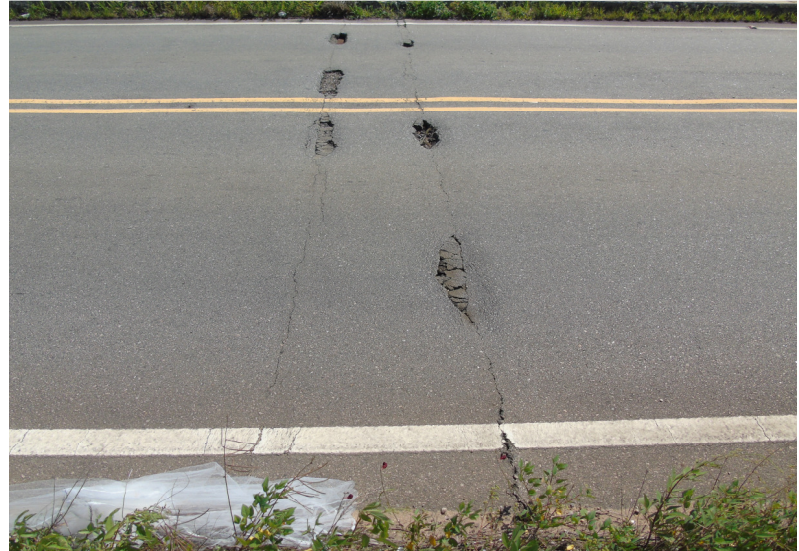

Figura 8 - Junta de dilatação danificada ou expelida.

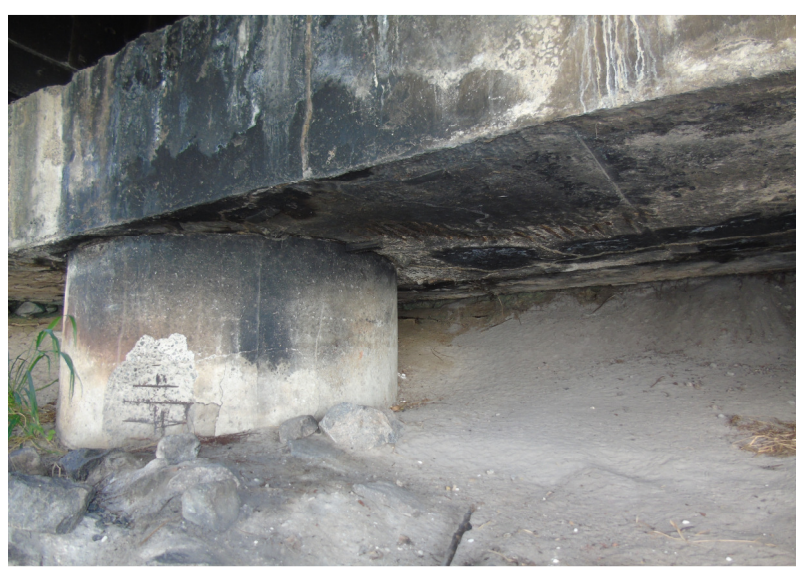

Figura 10 - Encontro frontal portante de concreto armado com manchas de fogo.

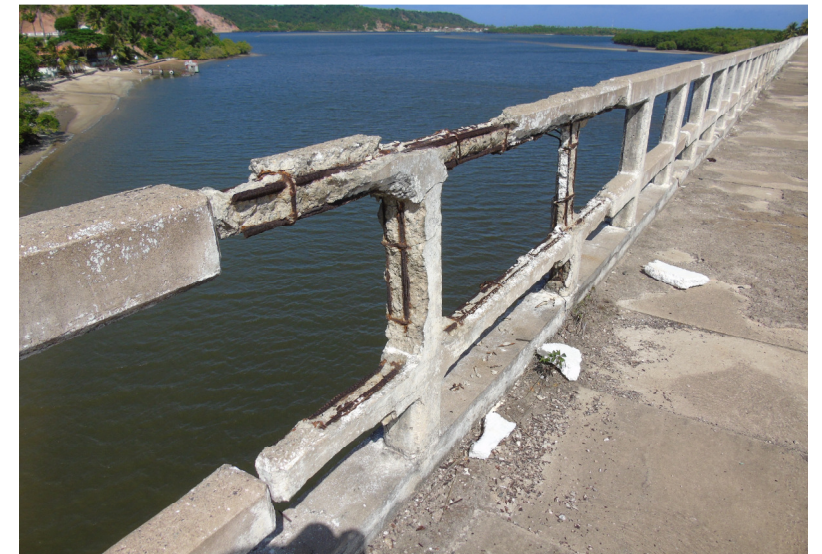

Figura 9 - Guarda corpo com armadura exposta.

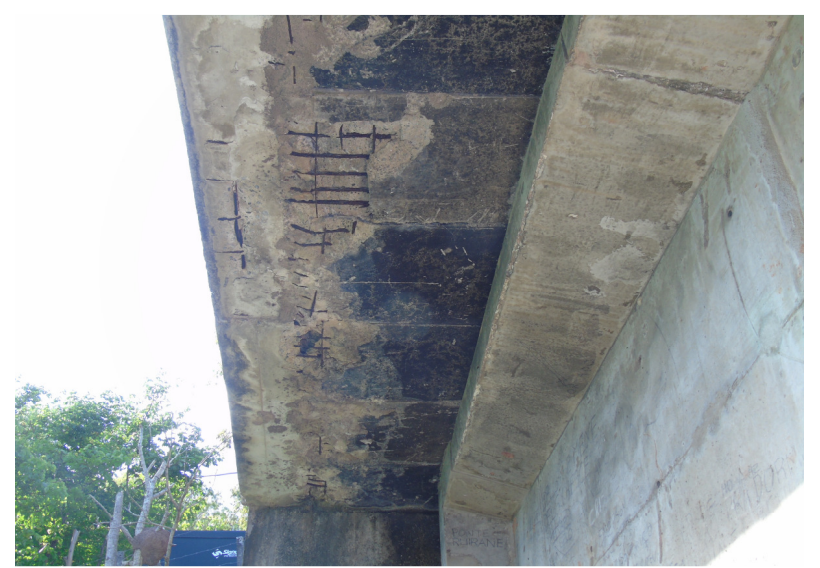

Figura 11 - Laje com concreto desagregado e armadura expostas e manchas de umidade devido a pingadeira ineficiente. 


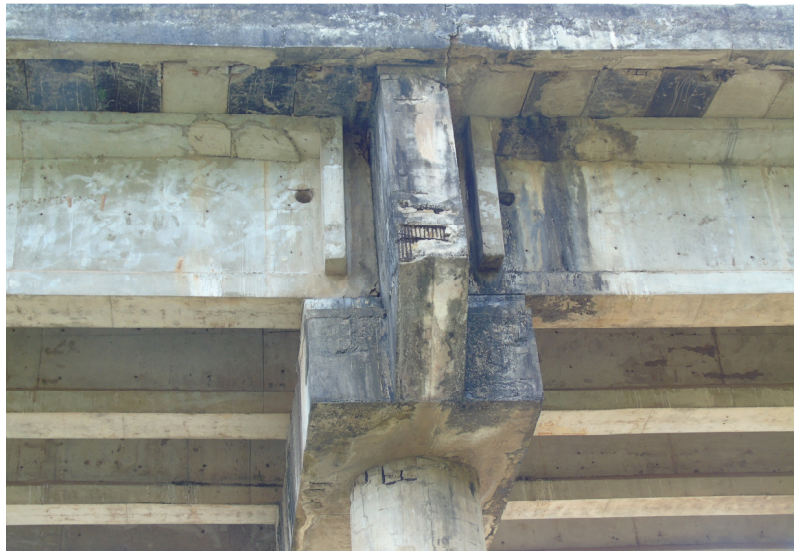

Figura 12 - Travessa de apoio de concreto armado com infiltração no concreto e concreto desagregado com armadura exposta.

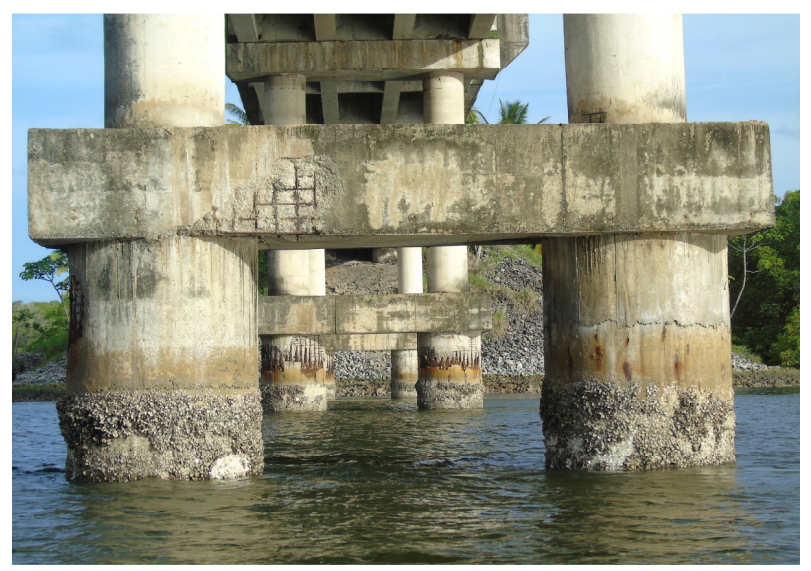

Figura 14 - Bloco de coroamento de concreto armado com concreto desagregado com armadura exposta e perca de seção da armadura.

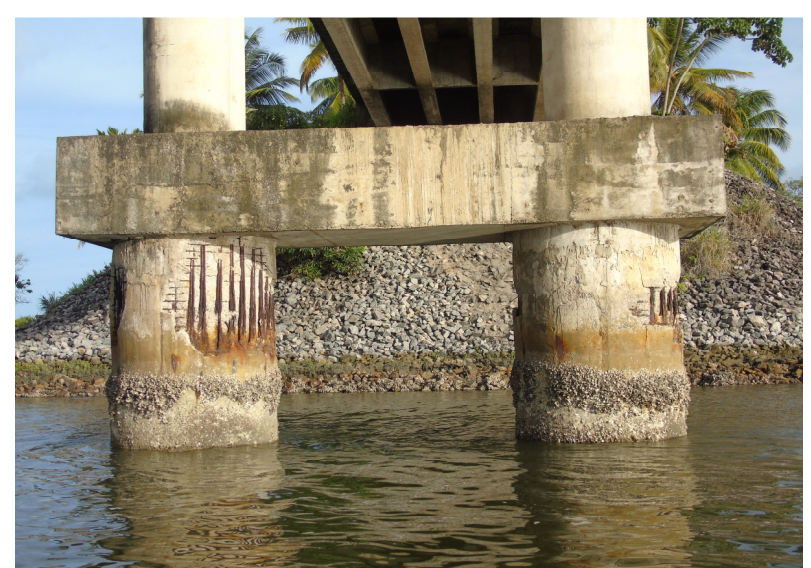

Figura 16 - Tubulão de concreto armado com concreto desagregado com armaduras expostas e com perca de seção devido à ausência de sua proteção com camisa metálica.

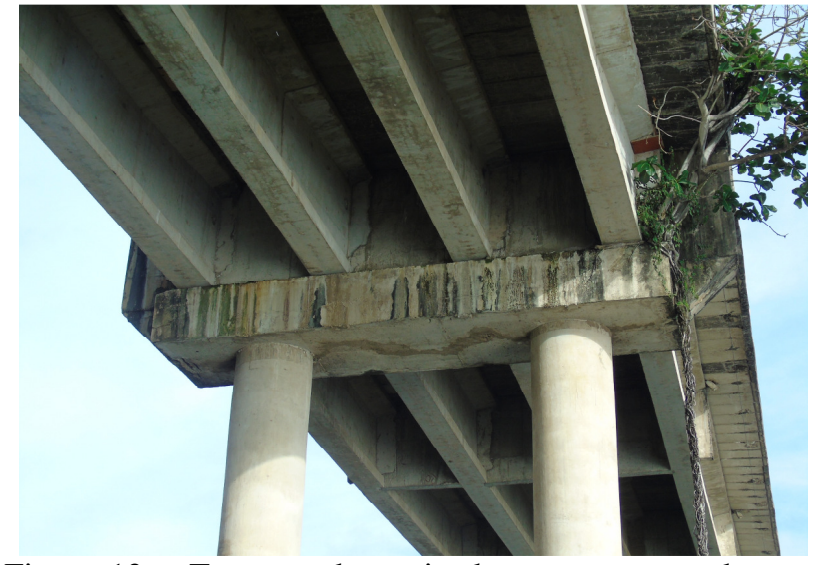

Figura 13 - Travessa de apoio de concreto armado com infiltração no concreto e manchas de umidade devido a junta de dilatação danificada.

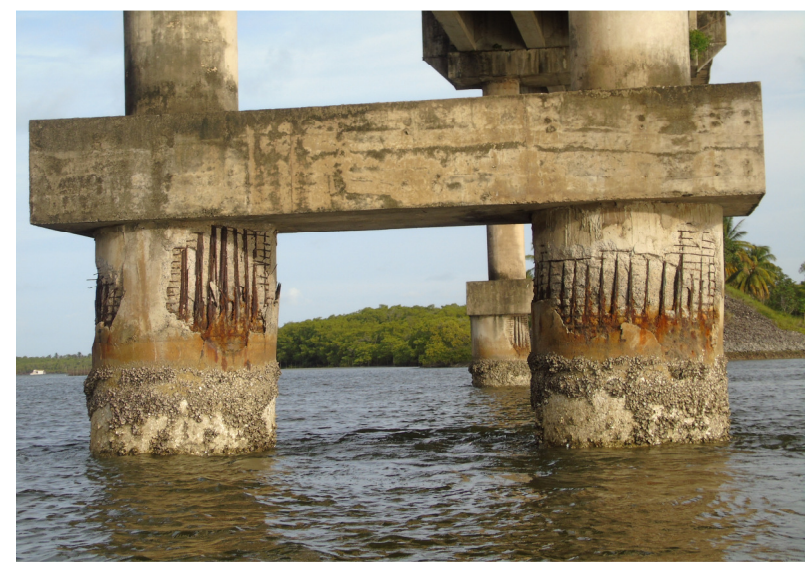

Figura 15 - Tubulão de concreto armado com concreto desagregado com armaduras expostas e com perca de seção devido à ausência de sua proteção com camisa metálica.

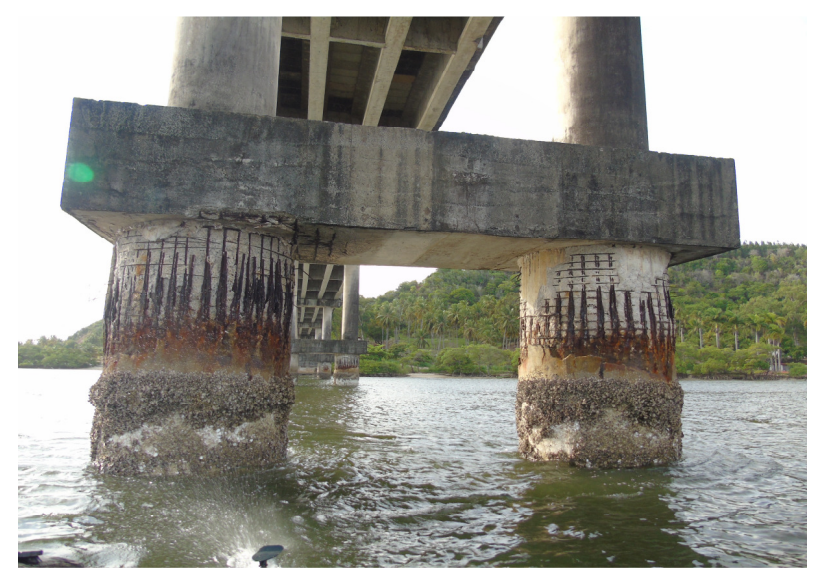

Figura 17 - Tubulão de concreto armado com concreto desagregado com armaduras expostas, rompidas e com perca de seção devido à ausência de sua proteção com camisa metálica.

Toda a estrutura de concreto deve resistir às intempéries ambientais, sua durabilidade está integrada ao concreto que envolve e protege as armaduras do ambiente. Torna-se necessário sempre especificar adequadamente a sua qualidade como sua resistência, fator água/cimento, bem como oas combrimentos das armações nos elementos estruturais. 
Pode-se mencionar que a norma ABNT NBR 6118:2014, descreve que a definição da classe ambiental é fundamental na concepção de projetos estrutura e durante sua vida útil, influeciando os valores mínimos de resistencia e o cobrimento da armadura. A classificação está relacionada às ações físicas e químicas que atuam sobre as estruturas de concreto, independente das ações mecânicas, das variações volumétricas de origem térmica, da retração hidráulica e outras previstas no dimensionamento das estruturas de concreto. Em análise na obra objeto desse artigo, pode-se afirmar que sua classe de agressividade ambiental é IV, muito forte, uma vez que a estrutura recebe respingos de maré. Conforme tabela abaixo está especificada as classes de agressividade ambiental.

Tabela 6 - Classes de agressividade ambienta (CCA) segundo ABNT NBR 6118:2014.

\begin{tabular}{|c|c|c|c|}
\hline $\begin{array}{c}\text { Classe de agressividade } \\
\text { ambiental }\end{array}$ & Agressividade & $\begin{array}{l}\text { Classificação geral do tipo de ambiente } \\
\text { para efeito de Projeto }\end{array}$ & $\begin{array}{c}\text { Risco de deterioração da } \\
\text { estrutura }\end{array}$ \\
\hline \multirow{2}{*}{ I } & \multirow{2}{*}{ Fraca } & Rural & \multirow{2}{*}{ Insignificante } \\
\hline & & Submersa & \\
\hline II & Moderada & Urbana $^{\mathrm{a}, \mathrm{b}}$ & Pequeno \\
\hline \multirow{2}{*}{ III } & \multirow{2}{*}{ Forte } & Marinha $^{a}$ & \multirow{2}{*}{ Grande } \\
\hline & & Industrial $^{\mathrm{a}, \mathrm{b}}$ & \\
\hline \multirow{2}{*}{ IV } & \multirow{2}{*}{ Muito Forte } & Industrial $^{\mathrm{a}, \mathrm{c}}$ & \multirow{2}{*}{ Elevado } \\
\hline & & Respingos de maré & \\
\hline
\end{tabular}

(a) Pode-se admitir um microclima com uma classe de agressividade mais branda (uma classe acima) para ambientes internos secos (salas, dormitórios, banheiros, cozinhas e áreas de seviço de apartamentos residências e conjuntos comerciais ou ambientes com concreto revestido com argamassa e pintura).

(b) Pode-se admitir uma classe de agressividade mais branda (uma classe acima) em obras em regiões de clima seco, com umidade média relativa do ar menor ou igual a $65 \%$, partes da estrutura protegidas da chuva em ambientes predominantemente secos ou regiões onde raramente chove.

(c) Ambientes quimicamente agressivos, tanques industriais, galvanoplastia, branqueamento em indústrias de celulose e papel, armazéns de fertilizantes e indústrias químicas.

A luz das informações contidas nas normas vigentes e experiência dos autores, será apresentado na tabela a seguir as notas referentes aos elementos e os dados complementares indicados $\left(^{*}\right)$ pelos autores.

Tabela 7 - Notas de classificação dos elementos.

\begin{tabular}{|c|c|c|c|c|}
\hline \multirow{2}{*}{ Elementos } & \multirow{2}{*}{ Sistema Estrutural } & \multicolumn{3}{|c|}{ Notas de Classificação } \\
\cline { 3 - 5 } & & Parâmetros Estruturais & Parâmetros Funcionais & Parâmetros Durabilidade \\
\hline Guarda Corpo & Complementar & - & 3 & 3 \\
\hline Junta de dilatação & Complementar* & - & $2^{*}$ & $2^{*}$ \\
\hline Laje & Secundário & 3 & - & 3 \\
\hline Viga & Principal & 4 & - & 4 \\
\hline Transvesina & Secundário & 5 & - & $3^{*}$ \\
\hline Encontro & Principal* & $3^{*}$ & - & $5^{*}$ \\
\hline Aparelho de Apoio & Secundário & 5 & - & 3 \\
\hline Travessas & Principal & 3 & - & 3 \\
\hline Pilar & Principal & 3 & - & 2 \\
\hline Blocos & Principal & 2 & - & 1 \\
\hline Tubulões & Principal & 1 & - & \\
\hline
\end{tabular}

Elementos destacados (*) são algumas recomendação em complemento a norma ABNT NBR 9452/2016.

Junta de dilatação: Sendo considerado um elemento importante na estrutura em questão de sua movimentação e estanqueidade, não se trata de um elemento estrutural e sim funcional. As anomalias surgem devido a ausência de manutenção e a sobreposição nos trabalhos de recapeamento do pavimento, posterior causando a percolação de águas nos elementos como viga, transversina e travessa de apoio. Encontro portante parede frontal de concreto armado: Se tratando de uma estrutura isostática, o elemento deve ser considerado nos parâmentros do sistema estrutural como Principal.

Aparelho de Apoio: As notas referente aos parâmetros de durabilidade recomenda-se considerar para cada tipo de aparelho de apoio, o tipo de material correlacionado a sua vida útil.

Destacando-se os dois principais elementos com a menor nota estrutural e de durabilidade, os blocos de coroamento e os tubulões, encontram-se com concreto segregado em regiões de tensões de compressão, armadura principal exposta, e corroída com perda de seção, além de infiltração no concreto. Vale lembrar conforme descrito no trabalho acima, as 
causas das patologias nos tubulões, está relacionada a uma deficiência estrutural, como a ausência de camisa metálica, tal fato, está vinculado à ausência de estudos e indicação no projeto na sua época de construção.

\section{CONSIDERAÇÕES FINAIS}

Ao decorrer deste trabalho, foi possível efetuar uma análise do estado de conservação da ponte e, deste modo, concluir que a obra de arte, em seu estado atual, não se encontra em condições de utilização. Observa-se que a manutenção precária e erros de projetos na época de execução da obra permitiu que várias patologias surgissem, compromentendo a capacidade de resistênca da obra. A ponte apresentou patologias que requerem serviço de manutenção com urgência. Logo, recomenda-se que haja paralização do trafego e interdição da mesma, até a sua recuperação.

As ações preventivas e corretivas do estrutural exige recomposição e complementação dos cobrimento das armaduras com argamassa polimérica base cimento projetada nas superfícies das lajes, transversinas, pilares e vigas, visto que, nesses locais, há insuficiência do cobrimento, carbonatação, corrosão em armaduras, desplacamento do concreto e fissuras.

O principal dano obervado na estrutura é o dos tubulões de concreto armado. Portanto, deve-se realizar reforço na fundação para recuperar os elementos degradados e aumentar a área de apoio. Para esse reforço é necessário realizar uma prévia elaboração de trabalhos de cálculo estrutural e como solução, necessita de implantação de camisa metálica nos tubulões.

Com relação a estética e requisitos funcionais da OAE é necessário fazer uma recuperação do aterro de acesso com contenção, implantar uma calha de drenagem para as águas pluviais, substituir os drenos danificados e realizar a limpeza dos que se encontram obstruídos, além de realizar uma pintura geral.

O desenvolvimento do presente estudo possibilitou analisar a ponte e apontar que a degradação está associada ao meio onde a ponte se situa, além do fator idade, falta de controle tecnológico na execução da obra, falha de projeto devido a ausência de camisa metálica no tubulão, aos cobrimentos dos elementos estruturais não serem suficientes e, falta de inspeção rotineira para quantificar as patologias e corrigir conforme as necessidades. Portanto, conclui-se que se houvesse um programa de manutenção adequado, a ponte apresentaria patologias menores.

Após a inspeção da OAE apresentada neste estudo, o DER/AL iniciou-se os trabalhos de reabilitação da ponte.

\section{REFERÊNCIAS}

ALVES, V. R., LOURENÇO, L.C., JORDY, J.C., MENDES, L.C. Parâmetros de avaliação de patologias em obrasde-arte especiais. Revista Engenharia Civil, Braga, n. 34, p. 5-14, 2009. Disponível em: < http://www.civil.uminho.pt/revista/artigos/n34/Pag_5-14.pdf.>. Acesso em: 10 jan. 2020.

AMORIM, D. L. N. F.; BARBOZA, A. S. R.; BARBIRATO, J. C. C. Técnica de analogia de grelha associada a um modelo de pórtico para análise do comportamento de sistemas estruturais de pontes. V Congresso Brasileiro de $\begin{array}{llllll}\text { Pontes e } & \text { Estruturas. } & \text { Rio } & \text { Janeiro, } & \text { Disponível }\end{array}$ https://www.researchgate.net/publication/280082311_TECNICA_DE_ANALOGIA_DE_GRELHA_ASSOCIADA_A_ UM_MODELO_DE_PORTICO_PARA_ANALISE_DO_COMPORTAMENTO_DE_SISTEMAS_ESTRUTURAIS_D E_PONTES >. Acesso em: 16 jan. 2020.

ARAUJO, A.; PANOSSIAM, Z. Durabilidade de estruturas de concreto e ambiente marinho: estudo de caso. INTERCORR 2010. Fortaleza, Ceará. Disponível em: <https://www.ipt.br/download.php?filename=201Durabilidade_de_estruturas_de_concreto.pdf>. Acesso em: 16 jan. 2020.

ASSOCIAÇÃO BRASILEIRA DE NORMAS TÉCNICAS. NBR 9452: Inspeção de Pontes, Viadutos e Passarelas de Concreto - Procedimento. Rio de Janeiro, 2016. 
BRASIL. Departamento Nacional de Infraestrutura de Transportes. Inspeção em pontes e viadutos de concreto armado e protendido. Rio de Janeiro, RJ, 18p. 2004. Disponível em: < http://ipr.dnit.gov.br/normas-emanuais/normas/procedimento-pro/dnit010_2004_pro.pdf>. Acesso em: 16 jan. 2020.

BRASIL. Departamento Nacional de Infraestrutura de Transportes. Manual de inspeção de pontes rodoviárias. 2.ed. Rio de Janeiro, RJ, 255p. 2004. Disponível em: < http://ipr.dnit.gov.br/normas-emanuais/manuais/documentos/709_manual_de_inspecao_de_pontes_rodoviarias.pdf >

CAMPOS, P. M. F. Deteção de dano em pontes integrando algoritmos de aprendizagem, modelos de elemento finitos e dados da monitorização estrutural. Dissertação. Universidade Lusófona de Humanidades e Tecnologias. Lisboa, 2018.

Disponível em:< http://recil.grupolusofona.pt/bitstream/handle/10437/8783/Dissertacao\%20Pedro\%20Campos\%20\%2823\%29.pdf?sequ ence $=1>$. Acesso em: 16 jan. 2020 .

LAVÔR, T. F. A.; LINHARES, L.R.S., SAMTOS, R.A. Análise Patológica em uma ponte de concreto armado: identificação das causas e possíveis soluções. IXCBPE - IX Congresso Brasileiros de pontes e estruturas. Rio de Janeiro. Disponível em: http://www.repositorio.ufal.br/bitstream/riufal/3747/1/An\%C3\%A1lise\%20das\%20manifesta\%C3\%A7\%C3\%B5es\%20 patol\%C3\%B3gicas\%20em\%20pontes\%20de\%20concreto\%20armado\%3A\%20estudo\%20de\%20caso.pdf>

SANTOS, C.F.S. Patologias de estruturas de concreto armado. Trabalho de Conclusão de Curso. Universidade Federal de Santa Maria, Santa Maria, RS. 2014. Disponível em:< http://coral.ufsm.br/engcivil/images/PDF/2_2014/TCC_CAMILA\%20FREITAS\%20DOS\%20SANTOS.pdf > 